\title{
재난안전전문가 전문성 강화방안 \\ Strengthening Strategy for Professional Managers of Disaster Prevention and Safety
}

\author{
권기환* - 이원호** · 이승수*** \\ Gwon, Gihwan*, Yi, Waonho**, and Lee, Sungsu***
}

\begin{abstract}
The lack of awareness of disaster safety management lowers the priority of work and the lack of professionalism due to rotational practices are pointed out as the greatest problem in the disaster management in Korean government. Furthermore, education and training on disaster safety management is very weak with little opportunity, resulting in the more problem. In addition, the performance management of disaster safety management such as development of performance indicators and lack of compensation for achievement is not properly performed. Therefore, in this paper, we investigate concrete measures to improve the expertise of domestic disaster safety specialists. We conduct literature reviews and surveys with questionnaires to confirm the professionalism of public officials in charge of disaster safety management, In this paper, we propose a plan to strengthen the expertise of disaster safety specialists by analyzing the recruitment, placement and performance evaluation of public officials in the disaster safety field, and the current status and problems of actual operation.
\end{abstract}

Key words : Disaster Prevention and Safety Manager, Professionalism, Performance Management

\section{요 지}

재난안전관리에 대한 인식부족으로 업무의 우선순위가 낮고, 순환보직으로 인한 전문성 결여가 가장 큰 문제로 지적되고 있으며, 재난안전관리 관련 교육훈련 또한 매우 미약하여 담당 공무원의 전문역량을 제고할 수 있는 기회가 미흡하다. 또한, 성과지표의 개발 및 성과에 대한 보상의 미흡 문제 등 재난안전관리의 성과관리가 제대로 이루어지지 않고 있다. 따라서 이 논문에서는 국내의 재난안전전문가의 전문성을 향상시키기 위한 구체적 방안을 탐색하는 연구로서 문헌조사 및 설문조사 등을 실시하여 재난안전관리 전문 인력으로서 담당 공무원의 전문성을 확인하고, 이를 강화하기 위한 제도적 방안으로 재난안전 분야 공무원의 채용과 배치, 성과평가 등의 내용과 실제 운영의 현황과 문제점을 분석하여 구체적으로 재난안전전문가의 전문성을 강화하는 방안을 제시하였다.

핵심용어 : 재난안전전문가, 전문성, 성과관리

\section{1. 서 론}

최근 과학기술의 급속한 발전과 세계화·정보화의 급진 전에 따른 지식기반 경제로 전환되면서 개방성 - 이동성 • 가변성·불평등의 심화, 불확실성이 증가하는 위험사회를
살아가고 있다. 특히, 2001년 9・11테러를 계기로 새로운 유형의 위협과 재난에 동시에 대비하기 위하여 위기관리체제 전반에 대한 정비를 시작하였는데, 현대의 테러·재난 등에 대비하여 보다 폭넓은 정상적인 사회적 기능보호에 중점을 두고 관련기관을 통폐합하는 등 평시 재난대비 기관을 중심으

*정회원, 광운대학교 대학원 재난안전공학과 박사과정(E-mail: kgh2695@korea.kr)

Member, Ph.D Candidate, Department of Disaster Safety Engineering, Graduate School, Kwangwoon University

**교신저자, 정회원, 광운대학교 건축공학과 교수, 공학박사(Tel: +82-2-940-5195, Fax: +82-2-917-3578, E-mail: whyi@kw.ac.kr)

Corresponding Author, Member, Professor, Department of Architectural Engineering, Kwangwoon University

***정회원, 충북대학교 토목공학부 교수, 공학박사(E-mail : joshua@cbnu.ac.kr)

Member, Professor, School of Civil Engineering, Chungbuk National University 
로 재편되었다. 미국의 국토안보부(DHS: Department of Homeland Security), 영국의 비상대비사무처(CCS: The Civil Contingencies Secretariat), 러시아 비상사태부(EMERCOM: Emergency Control Ministry), 스웨덴 비상관리처(SEMA: The Swedish Emergency Management Agency) 등으로서, 이는 인권, 복지, 평화 등 인류의 보편적 가치를 보호하고자 하는 안보관의 변화와 비상관리기능의 통합성을 극대화하 여 국민편익 증진은 물론 서비스 향상을 꾀하였다. 그러나 국내의 경우 조직 내에서 관련 업무를 담당할 인력의 육성과 관리에 대한 관심은 상대적으로 부족하다. 특히, 중앙 및 지방부처의 재난안전관리 인력의 경우, 재난안전관리에 대 한 인식부족으로 업무의 우선순위가 낮고, 순환보직으로 인한 전문성 결여가 가장 큰 문제로 지적되고 있다. 이러한 상황에서 재난안전관리 관련 교육훈련 또한 매우 미약하여 담당 공무원의 전문역량을 제고할 수 있는 기회가 미흡하다. 따라서, 본 연구에서는 다음과 같은 세부 연구목표를 선정하 고 이에 대한 결과를 도출하고자 한다.

첫째, 재난안전관리 담당 공무원으로서의 전문성(Choi, 2003)을 분석한다.

둘째, 재난안전관리 전문 인력의 역량강화에 영향을 미치 는 요인(Oh, 2006)들을 조사하고 재난안전관리 공무원의 전문성 강화 요인으로서 채용과 배치, 성과관리의 영향성을 판단한다.

셋째, 재난안전관리 전문 인력의 역량 강화를 위해 필요한 제도(Kearney and Sinha, 1988; Choi and Chang, 2009)와 운영상의 대안을 마련하고 재난안전관리 공무원의 채용과 배치, 성과관리(Caiden, 1998) 등을 발전시키기 위한 구체적 대안을 제시한다.

\section{2. 재난안전관리 전문인력 운용현황 분석}

\section{1 방재안전직렬 운용}

1994년 10월 성수대교 붕괴사고, 1995년 4월 대구지하철
공사장 가스폭발사고, 1995년 6월 삼풍백화점 붕괴사고 등 으로 인해 정부는 1995년 7월 재난관리법을 제정하였고, 이에 맞추어 1995년 12월에는 기존의 풍수해대책법을 전부 개정하여 자연재해대책법을 제정하였다. 아울러 2004년 6 월 『재난 및 안전관리기본법』시행으로 종전의 방재계획과 재난관리계획을 「안전관리계획」으로 통합하여 중앙부처의 기본계획과 집행계획, 시·도 및 시·군·구 안전관리계획, 재난관리책임기관의 세부집행계획으로 구분하여 수립토록 하였다.

이러한 법체계를 근간으로 정부는 2012년부터 재난안전 분야 공무원의 전문성 향상을 위해 방재안전직렬을 신설하 였다. 행정안전부(MOIS, 2012)에 따르면, 이는 재난안전 공무원들이 일반행정직 또는 시설·공업직 공무원으로 이 루어지고, 순환보직 관행으로 전문성이 낮다고 인정되었기 때문이다. 방재안전직렬은 2014년 이후 해당 분야 전공자를 경력경쟁채용으로 신규채용하거나 기존 재직자의 전직 등 을 통해 운용하고 있다. Table 1은 방재안전직렬 운용계획을 나타낸 것이다.

\section{2 재난안전관리 전문 인력의 교육훈련}

법령상 재난안전관리 공무원은 Table 2 와 같이 교육훈련 을 받도록 되어 있다.

현재 국가민방위재난안전교육원, 중앙소방학교, 중앙공 무원교육원 등 여러 기관에서 다양한 재난상황 대비훈련에 도 불구하고 재난안전 담당 공무원, 소방, 해경, 경찰 등 각급 직종별로 교육·훈련하는 운영체계 이외에 복합적인 상황을 가정한 관계기관 합동 교육훈련과정이 미흡한 실정 이다. 재난안전 분야의 역량 제고는 정부의 기능 및 조직개편 이나 대응시스템의 개선뿐만 아니라 인적자원의 역량제고 가 병행되어야 한다는 점에서 특정 직종 또는 업무담당자 및 관리자 위주로 운영되고 있는 현재의 재난안전 교육훈련 프로그램은 개선되어야 한다.

Table 1. Operation Plan for Disaster Prevention and Safety Division

\begin{tabular}{|c|c|}
\hline Section & Contents \\
\hline Back-ground & $\begin{array}{l}\text { - Ministry of the interior and safety (MOIS) and National Fire Agency (NFA) consist of about } 2400 \\
\text { central government officials in charge of disaster prevention and safety services, who are } \\
\text { specialized in general administrative work, facilities, industrial work, etc. and in general lack of } \\
\text { expertise due to rotation positioning. } \\
\text { - Disaster prevention safety division as a technical group is newly established to effectively deal } \\
\text { with disasters of diversification, large scale and complexity }\end{array}$ \\
\hline Recruit Plan & $\begin{array}{l}\text { - Recruitment of career competitors in the relevant field, consideration of ministry demand after } 2014 \\
\text { - In the case of the existing employees, the disaster prevention and safety transfer in line with the } \\
\text { desire of the applicant. (In the attached clause of Article } 5 \text { of the civil servant, the general public } \\
\text { employee in charge of disaster prevention safety related job field) }\end{array}$ \\
\hline Amendment Plan & $\begin{array}{l}\text { - February 2013: Revision of the appointment of civil servants } \\
\text { - April 2013: Revision of the civil servant appointment test } \\
\text { - May 2013: Amendment of appointment order of local public officials }\end{array}$ \\
\hline
\end{tabular}


Table 2. Public Officer Education and Training

\begin{tabular}{|c|c|}
\hline Section & Contents \\
\hline To whom & $\begin{array}{l}\text { - Public officials or staff responsible for disaster management and safety management at the agency } \\
\text { responsible for disaster management }\end{array}$ \\
\hline By whom & - Minster of MOIS \\
\hline Agency & $\begin{array}{l}\text { - Educational institutions with professional and institutional standards } \\
\text { - MOIS related central administrative agency or public officials of cities and provinces } \\
\text { - Educational institutions designated by the Minister of Public Administration and Security as private } \\
\text { educational institutions with educational performance in disaster and safety management field }\end{array}$ \\
\hline Type & $\begin{array}{l}\text { - Professional training: manager of disaster management and safety management department } \\
\text { - Specialist training for practitioners: Personnel or employees of a department in charge of disaster } \\
\text { management and safety management at a disaster management institution, }\end{array}$ \\
\hline $\begin{array}{l}\text { Time } \\
\text { Frame }\end{array}$ & $\begin{array}{l}\text { - Education period of professional education is within } 3 \text { days } \\
\text { - New education: Within } 1 \text { year after taking the job } \\
\text { - Regular training: Every two years after receiving new training }\end{array}$ \\
\hline
\end{tabular}

Table 3. Overview of the Survey

\begin{tabular}{c|l}
\hline Section & \multicolumn{1}{c}{ Contents } \\
\hline Sample & - Central and local government officiails for disaster prevention safety management duties \\
\hline Sample Size & -318 officials \\
\hline Sample Extraction & - Sampling through the list of relevant public officials (website of each institution) \\
\hline $\begin{array}{c}\text { Survey } \\
\text { Method }\end{array}$ & - Web survey with FAX and E-mail \\
\hline Tool & - Web surveys (parallel fax and email surveys) \\
\hline Survey Contents & $\begin{array}{l}\text { - Evaluation of current and required expertise of disaster prevention safety management officers } \\
\text { - Recruitment, placement, training and evaluation of disaster prevention safety management officials } \\
\text { and alternative evaluation }\end{array}$ \\
\hline Period & \begin{tabular}{l} 
From September 1, 2014 to October 10, 2014 \\
\hline
\end{tabular}
\end{tabular}

\section{3 재난안전관리 전문 인력을 통한 상태조사}

재난안전관리 공무원 설문조사는 중앙정부의 경우 재난 안전관리 총괄부처인 행정안전부와 각 부처의 재난안전 업무 관련 공무원(산업안전, 보건안전, 해상안전, 산림, 기상 등), 각 부처의 재난안전 총괄업무 담당공무원(비상안전기 획관 등) 등을 포함하였고, 지방정부의 경우 재난안전관리 관련 부서(재난, 안전, 건축, 토목, 교통, 소방 등)에서 근무하 는 공무원 등을 대상으로 하였으며, 설문조사의 개요는 Table 3 과 같다.

\subsection{1 재난안전 인력의 현재 전문성 분석}

재난안전 인력의 전문성 분석은 전문지식 평가, 경험 평가, 협력 및 소통 평가, 개인적 자질 평가 등 총 4개의 평가항목을 토대로 조사하였다. 각 평가 항목별 설문결과는 Figs. 1 4와 같다.

Fig. 1의 전문지식 평가에서는 '재난안전관리 이론/기술
등의 전문지식', '각 정책분야 이론/기술 등의 전문지식', ‘행정/정책과정 이론/기술 등의 전문지식' 등 3 가지 항목 모두 보통이 가장 높게 나타났다.

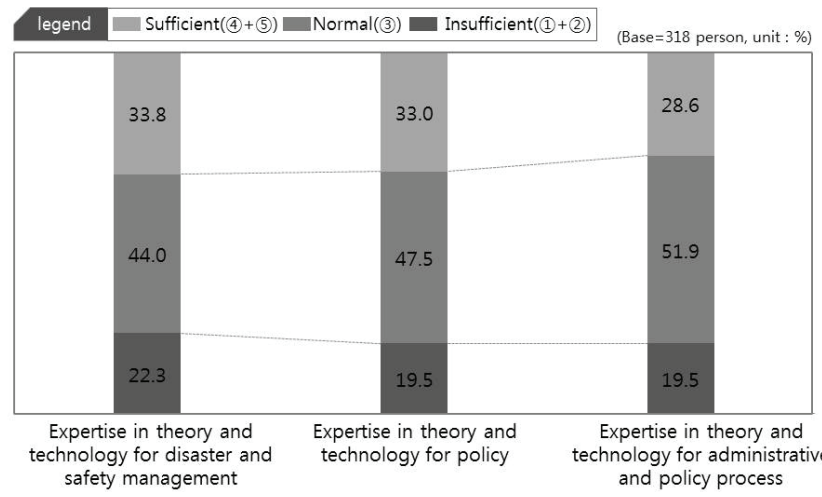

Fig. 1. Current Expertise Evaluation of Disaster Prevention Safety Personnel (expertise) 


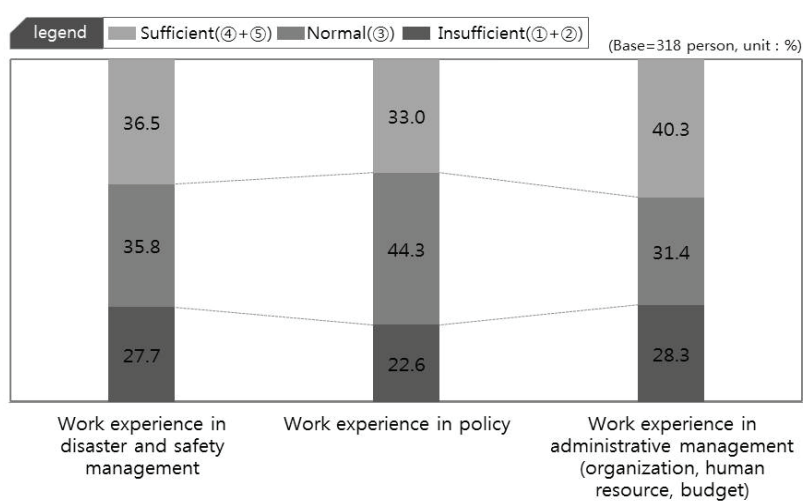

Fig. 2. Current Expertise Evaluation of Disaster Prevention Safety Personnel (experience)

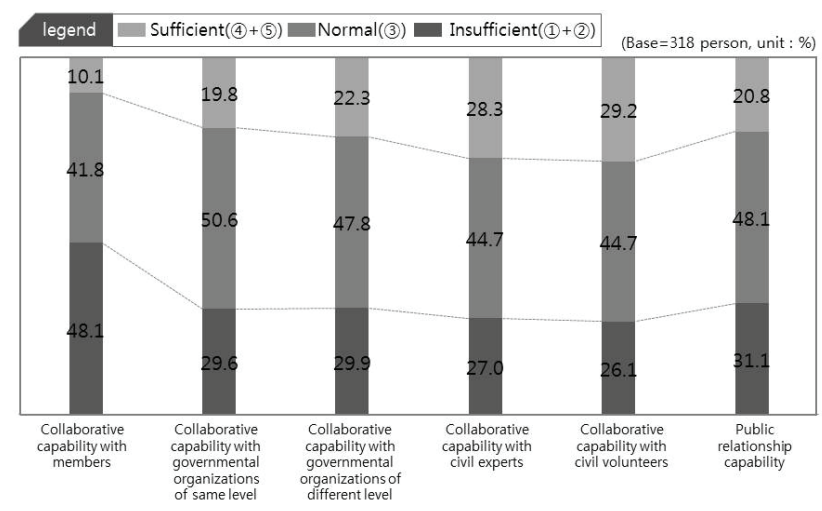

Fig. 3. Current Expertise Evaluation of Disaster Prevention Safety Personnel (cooperation and communication)

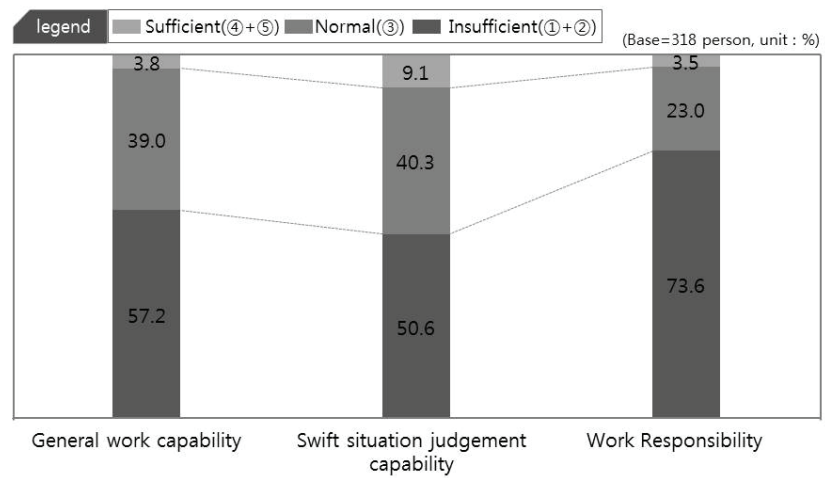

Fig. 4. Current Expertise Evaluation of Disaster Prevention Safety Personnel (personal qualities)

Fig. 2의 경험 평가 항목에서는 '재난안전관리 이론/기술 등의 현재 전문성', '각 정책분야 업무경험 등의 전문지식', ‘일반 행정관리 업무경험의 현재 전문성' 등 3 가지 항목 모두 미흡이 가장 높게 나타났다.

Fig. 3의 협력 및 소통 평가에서는 ‘조직 내 구성원 간 협업능력'의 경우 충분이 가장 높게 나타났으며, '민간 전문 가와의 협업능력'의 경우 미흡과 충분이 비슷한 수준으로 나타났고, ‘대국민 소통 능력'의 경우 보통이 높게 나타났다.
Fig. 4의 개인적 자질 평가에서는 '일반적인 업무 수행 능력', ‘빠른 상황 판단 능력', '업무에 대한 책임감 등 3 가지 모두 충분이 미흡보다 높게 나타났다.

\subsection{2 재난안전 인력의 필요 전문성 분석}

재난안전 인력의 필요 전문성 분석은 전문지식 평가, 경험 평가, 협력 및 소통 평가, 개인적 자질 평가 총 4가지 항목을 토대로 조사하였다. 각 항목별 설문결과는 Figs. 5 8과 같다.

Fig. 5의 전문지식 평가에서는 '방재안전관리 이론/기술 등의 전문지식', '각 정책분야 이론/기술 등의 전문지식', ‘행정/정책과정이론/기술 등의 전문지식' 등 3 가지 항목 모 두 필요가 높게 나타났다.

Fig. 6의 경험 평가에서는 '재난안전관리 업무/경험 등의 전문지식', ‘각 정책분야 업무경험', ‘일반 행정관리 업무경 험'의 경우 필요가 미흡보다 높게 나타났다.

Fig. 7의 협력 및 소통 평가에서는 '조직 내 구성원 간 협업 능력', ‘동일 수준 정부조직과의 수평적 협업능력', ‘상/하위 정부조직과의 수직적 협업능력, '민간 전문가와의 협업능력', ‘민간 자원봉사자와의 협업능력', ‘대국민 소통 능력' 총 6가지 항목에 대해 모두 필요가 미흡보다 높게 나타났다.

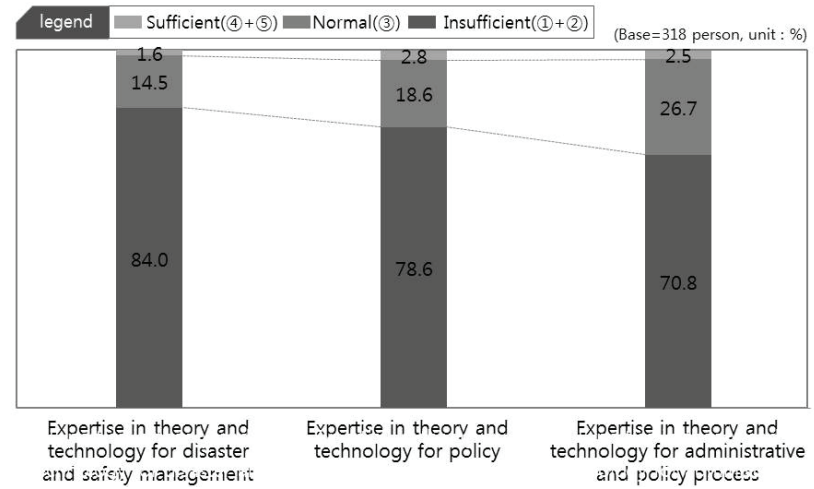

Fig. 5. Assessment of Required Expertise of Disaster Prevention Safety Personnel (expertise)

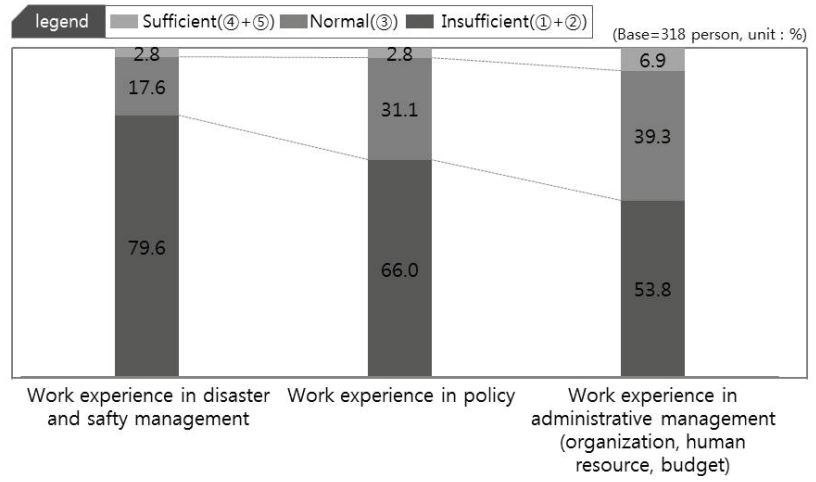

Fig. 6. Assessment of Required Expertise of Disaster Prevention Safety Personnel (experience) 


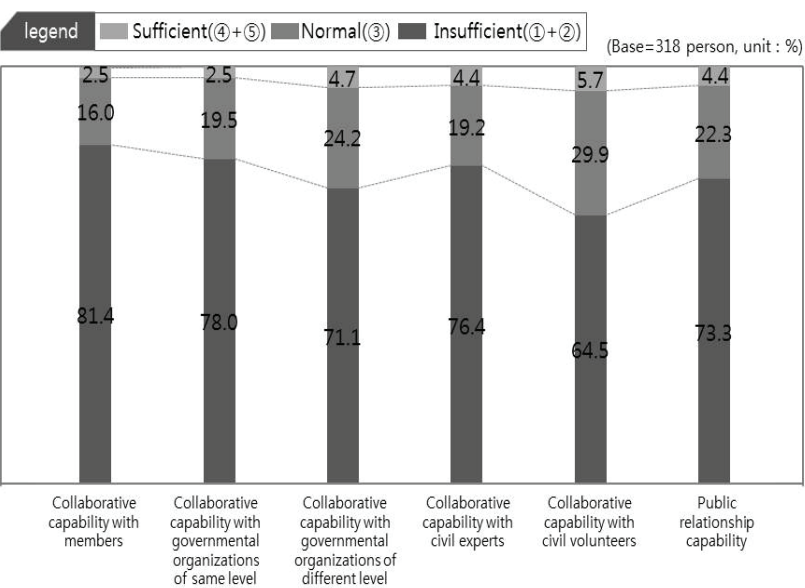

Fig. 7. Assessment of Required Expertise of Disaster Prevention Safety Personnel (cooperation and communication)
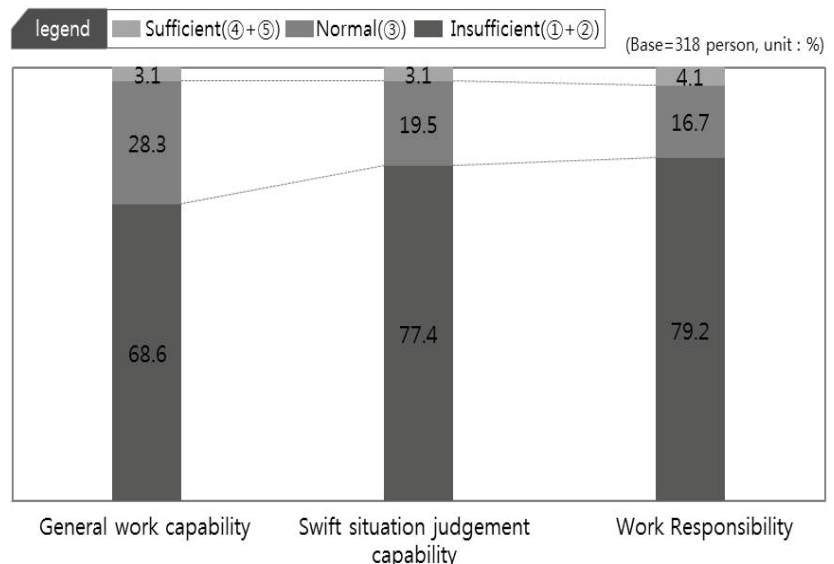

Fig. 8. Assessment of Required Expertise of Disaster Prevention Safety Personnel (personal qualities)

Fig. 8의 개인적 자질 평가에서는 '일반적인 업무 수행능 력, ‘빠른 상황 판단 능력, ‘업무에 대한 책임감' 모두 필요가 높게 나타났다.

\subsection{3 재난안전 기관의 현재 전문성 분석}

재난안전 기관의 현재 전문성 분석은 기관 전문성 평가 및 실/국 전문성 평가의 두 가지 항목을 토대로 조사하였으며, 설문결과는 Figs. 9 및 10 과 같다.

Fig. 9의 기관 전문성 평가에서는 '기관 내 충분한 자원'의 경우만 충분이 높게 나타났고, '기관장의 뛰어난 리더십', '기관 내 구성원 간 원활한 의사소통', '다른 정부조직과의 협력체계 구축', '민간과의 협력체계 구축' 등 4가지 항목 모두 미흡이 높게 나타났다.

Fig. 10 의 실/국 전문성 평가에서는 '실/국 내 충분한 자원'의 경우 '실/국 내 충분한 자원' 항목만 충분이 높게 나타났고, '실/국장의 뛰어난 리더십, '실/국 내 구성원 간 원활한 의사소통', '다른 정부조직과의 협력체계 구축', '민
간과의 협력체계 구축' 등 4 가지 항목모두 미흡이 높게 나타났다.

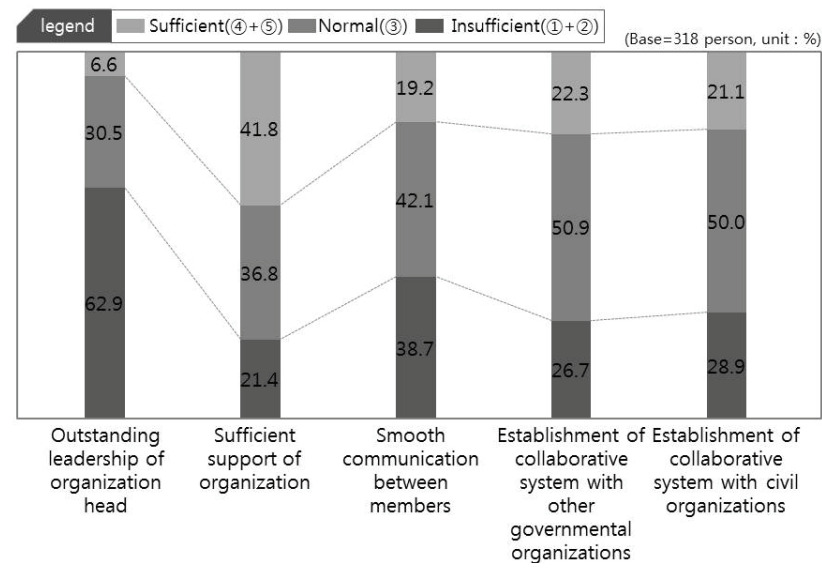

Fig. 9. Current Expertise Evaluation of the Disaster Prevention Safety Organization (institution)

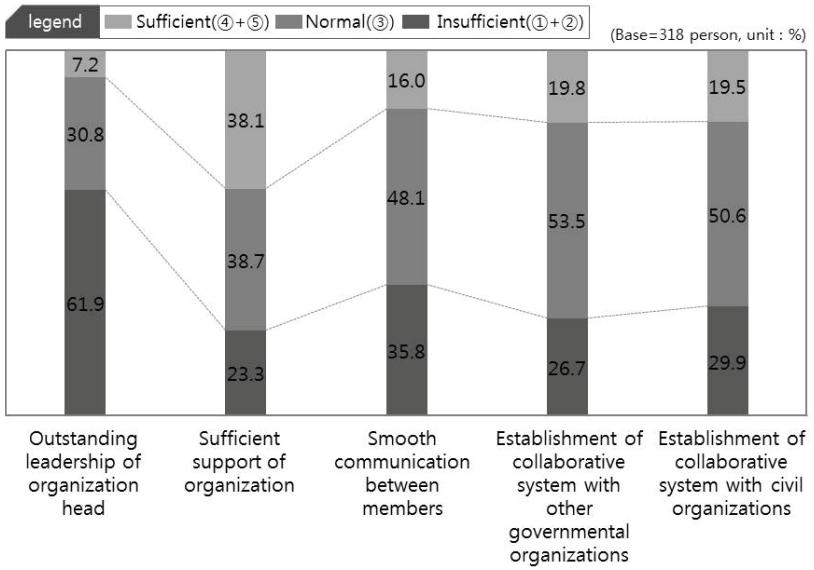

Fig. 10. Current Expertise Evaluation of the Disaster Prevention Safety Organization (division)

\subsection{4 재난안전 기관의 필요 전문성 분석}

재난안전 기관의 필요 전문성 분석은 기관 전문성 평가 및 실/국 전문성 평가 2가지 항목을 토대로 조사하였으며, 설문결과는 Figs. 11 및 12와 같다.

Fig. 11 의 기관 전문성 평가에서는 '기관장의 뛰어난 리더 십', '기관 내 충분한 자원', '기관 내 구성원 간 원활한 의사소통', '다른 정부조직과의 협력체계 구축', '민간과의 협력체계 구축' 등 5 가지 항목 모두 필요가 불필요보다 높게 나타났다.

Fig. 12 의 재난안전 조직의 현재 전문성 평가(실/국 전문 성)에서는 '실/국장의 뛰어난 리더십', '실/국 내 충분한 자 원', '실/국 내 구성원 간 원활한 의사소통', '다른 정부조직과 의 협력체계 구축', '민간과의 협력체계 구축' 등 5 가지 항목 모두 필요가 불필요 보다 높게 나타났다. 


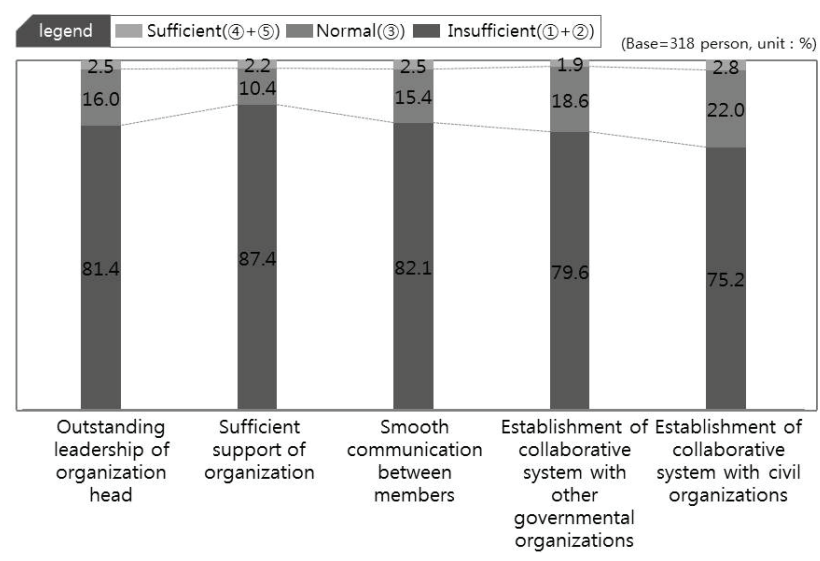

Fig. 11. Assessment of Required Expertise of Disaster Prevention Safety Organization (institution)

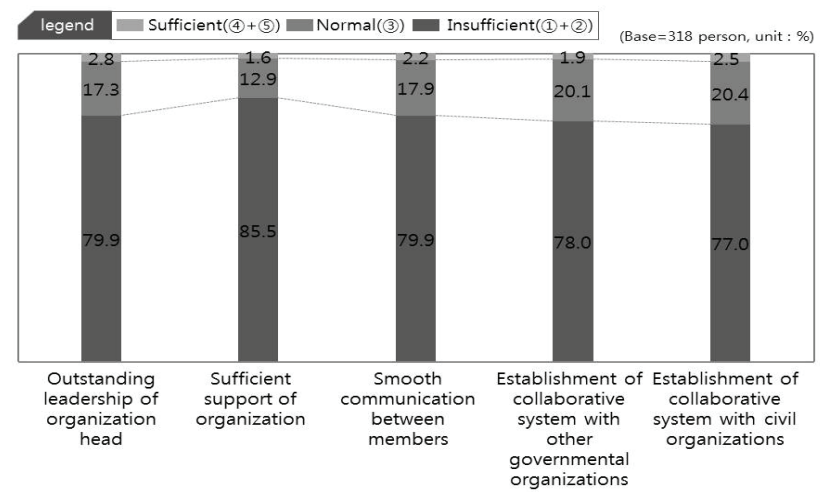

Fig. 12. Assessment of Required Expertise of Disaster Prevention Safety Organization (division)

\subsection{5 재난안전 인력의 전문성 저해요인 분석}

재난안전 인력의 전문성 저해요인 분석은 크게 직무요인, 개인적 요인, 조직, 환경요인 4 가지로 분류하였다. 각각의 분석은 항목별 1 순위의 평가항목의 결과와 각 순위의 단순합 계 (1순위 빈도, 2순위 빈도, 3순위 빈도의 합)인 종합순위로 나타내었으며, 종합순위의 퍼센트는 그래프의 가시성을 확 보하기 위해 $300 \%$ 를 기준으로 작성하였으며, 항목별 설문결 과는 Figs. 13 16과 같다.

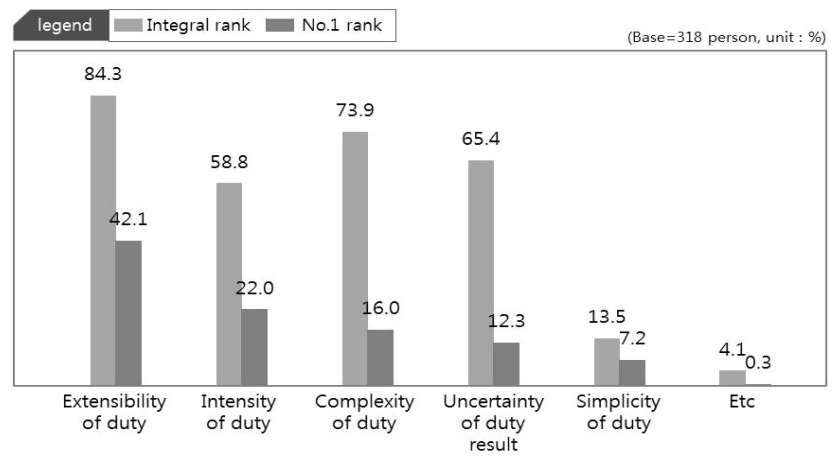

Fig. 13. Negative Factors of Disaster Prevention Safety Personnel (duty)

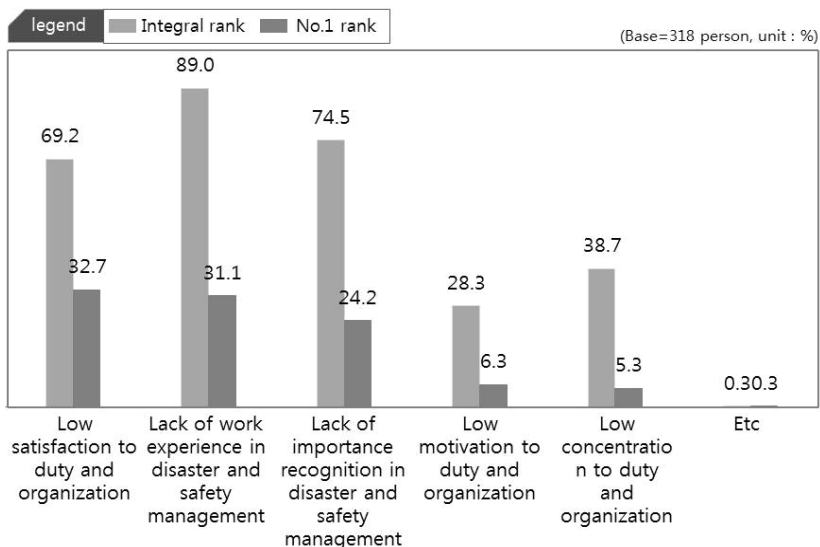

Fig. 14. Negative Factors of Disaster Prevention Safety Personnel (personal)

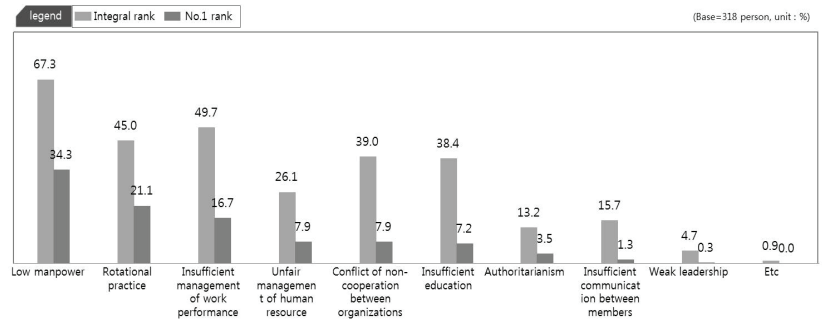

Fig. 15. Negative Factors of Disaster Prevention Safety Personnel (organization)

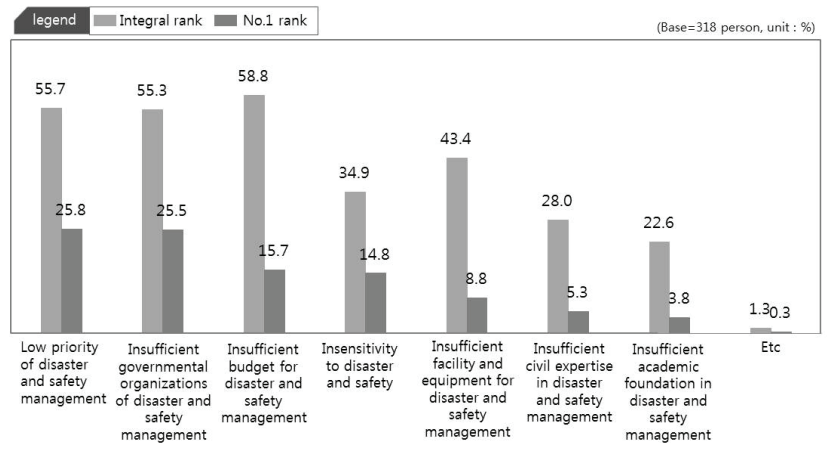

Fig. 16. Negative Factors of Disaster Prevention Safety Personnel (circumstance)

Fig. 13에서 직무요인 1순위의 경우 '직무의 광범위성' (42.1\%)이 가장 높고, '강한 업무 강도' $22.0 \%)$, ‘직무의 복잡성'(16.0\%), ‘업무 수행 결과의 불확실성’( $12.3 \%)$, ‘직무 의 단순성' $(7.2 \%)$ 순으로 높게 나타났다. 종합순위의 경우 ‘직무의 광범위성'(84.3\%), ‘직무의 복잡성'(73.9\%), ‘업무 수행 결과의 불확실성’(65.4\%), ‘강한 업무 강도’ $58.8 \%)$, ‘직무의 단순성' $(7.2 \%)$ 순으로 높게 나타났다.

Fig. 14 에서 개인요인 1 순위의 경우 '낮은 직무/조직만 족'(32.7\%), ‘재난안전 관리 업무 경험 부족'(31.1\%), ‘재난 안전의 중요성 인식 미흡' $24.2 \%)$, '낮은 업무 수행 동 기'(6.3\%), ‘낮은 직무조직 몰입'(5.3\%) 순으로 높게 나타났 
다. 종합순위의 경우 '재난안전 관리 업무 경험 부족'(89.0\%), '재난안전의 중요성 인식 미흡' $(74.5 \%)$, '낮은 직무/조직만 족'(69.2\%), ‘낮은 직무/조직 몰입'(38.7\%), ‘낮은 업무 수행 동기'(28.3\%) 순으로 높게 나타났다.

Fig. 15에서 조직요인 1순위의 경우 ‘조직인력부족’ $(34.3 \%)$, '순환보직관행'(21.1\%), '성과관리미흡’ $(16.7 \%)$, '불공정인 사'(7.9\%), '조직 간 갈등 또는 비협조'(7.9\%) 순으로 높게 나타났다. 종합순위의 경우 ‘조직 인력부족'(67.3\%), '성과 관리 미흡’(49.7\%), ‘순환보직 관행'(45.0\%), ‘조직 간 갈등 또는 비협조'(39.0\%), ‘교육훈련 미흡’(38.4\%) 순으로 높게 나타났다.

Fig. 16에서 환경요인 1순위의 경우 '재난안전 관리 정책 우선순위 낮음' $(25.8 \%)$, '재난안전 관리 정부조직체계 미 흡' $(25.5 \%)$, '재난안전 관리 재정투자 미흡' $(15.7 \%)$, '안전 불감증 문화'(14.8\%), '재난안전 관리 시설/장비 미흡’ $(8.8 \%)$ 순으로 높게 나타났다. 종합순위의 경우 '재난안전 관리 재정투자 미흡' $(58.8 \%)$, '재난안전 관리 정책 우선순위 낮 음' $(55.7 \%)$, '재난안전 관리 정부조직체계 미흡' $(55.3 \%)$, '재 난안전 관리 시설/장비 미흡'(43.4\%), '안전 불감증 문화' (34.9\%) 순으로 높게 나타났다.

\subsection{6 재난안전 인력의 채용 및 배치요인 분석}

재난안전 인력의 채용 및 배치요인 분석은 크게 순환보직 의 긍-부정적 결과와 성공적 재난안전 관리 업무 수행을 위해 필요한 기간, 전문성 제고를 위한 채용 - 배치 대안 평가 등 3 가지를 분석하였으며, 설문결과는 Figs. 17 19와 같다.

Fig. 17 에서 순환보직의 긍-부정적 결과에 대해 '그렇다' 는 응답은 '전문지식 습득의 어려움' $(62.9 \%)$, '경험 축적의 어려움'(61.3\%), '유관 지식의 습득'(56.0\%), '다른 부처/부 서 공무원과의 협업 역량의 제고'(44.7\%), ‘조직 차원의 거시 적 관점 습득' $(36.2 \%)$, ‘부서 내부 구성원 간 협업의 어려 움' $(31.1 \%)$ 순으로 나타났다.

Fig. 18 에서 성공적인 재난안전 관리 업무 수행을 위해 필요한 업무 기간은 ‘2-3년 미만’(31.1\%), ‘3-4년 미만' (28.6\%), '4년 이상'(23.9\%) 순으로 나타났다. 전체 평균적으 로는 3년 4개월 이상이 필요하다고 응답 하였다.

Fig. 19에서 전문성 제고를 위한 채용 - 배치 대안 평가 중 '필요하다'는 응답은 '재난안전 관리 전문직위 확대' (74.5\%), ‘재난안전 관리 직위유형별 보직관리 확대’(66.7\%), '방재안전직렬 확대’(64.5\%), ‘재난안전 관리부서의 신규인 력 우선선발권 부여' $(56.6 \%)$ 순으로 나타났다. '불필요하다' 는 응답은 '재난안전 관리 정부와 민간 간 인사교류 확대' (21.1\%), '재난안전 관리 지방정부 간 인사교류 확대’ $(20.1 \%)$, '재난안전 관리 중앙정부 부처 간 인사교류 확대’(17.3\%), ‘재난안전 관리 민간 전문가 채용'(17.3\%) 순으로 나타 났다.

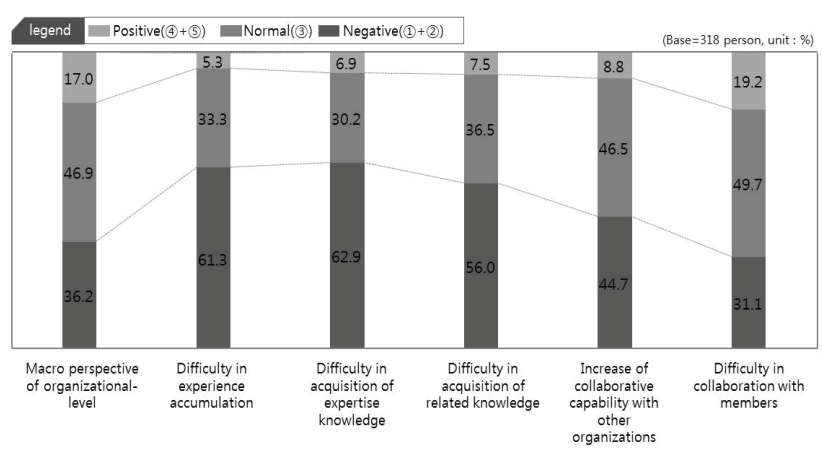

Fig. 17. Positive and Negative Consequences of Cyclical Practices of Disaster Prevention Security Personnel

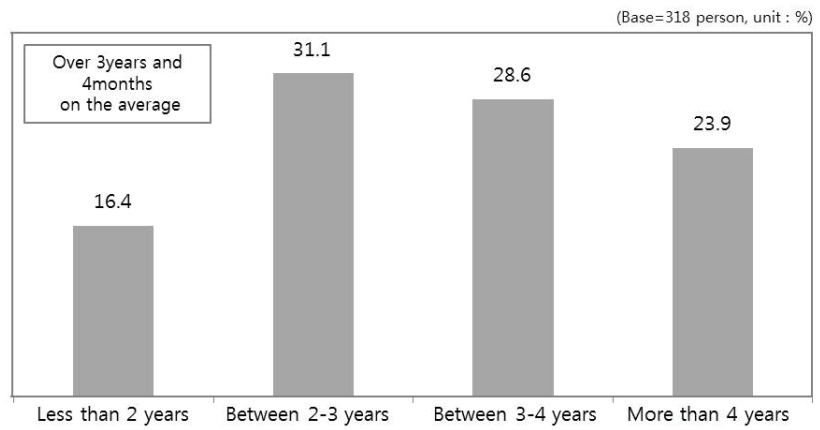

Fig. 18. Necessary Period for Successful Job Performance

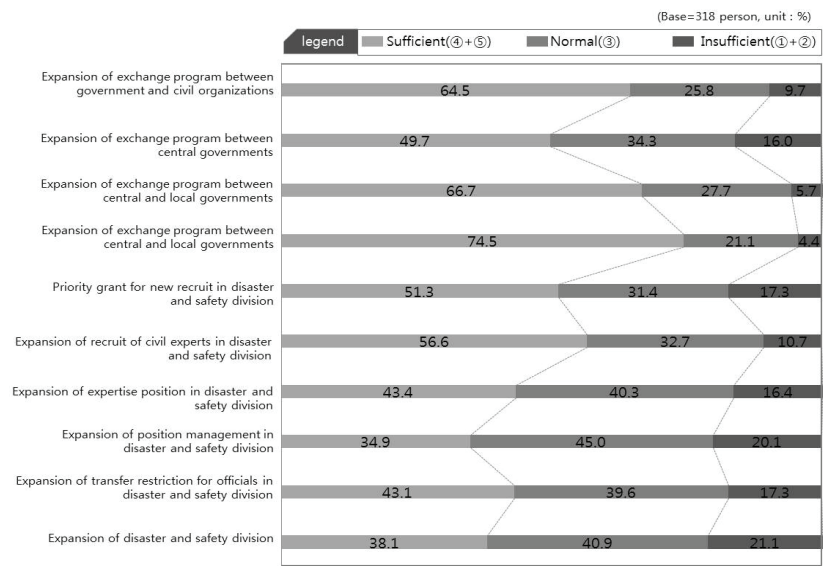

Fig. 19. Assessment of Alternatives for Recruiting and Disposal to Improve the Professionalism of Disaster Safety Management Civil Servants

\subsection{7 재난안전 인력의 성과관리 요인 인식}

재난안전 인력의 성과관리 요인 인식은 재난안전관리 공무원 성과관리의 문제 평가 및 재난안전 관리 공무원 성과관리의 개선 방안 평가 2가지를 조사하였으며, 설문결 과는 Figs. 20 및 21 과 같다.

Fig. 20 의 재난안전 관리 공무원의 성과관리 문제에 대한 평가에서는 긍정적 평가를 받은 항목으로는 '나의 상사는 성과에 따라 공정하게 평가한다.'(26.4\%), '내가 속한 기관은 성과에 따라 공정하게 평가한다.'(23.3\%) 등의 순이었으며, 
부정적 평가를 받은 항목으로는 '현재 성과달성에 따른 금전 적 보상은 충분하다.'(43.1\%), '나는 노력한 만큼 성과평가 점수를 받는다.'(34\%) 등의 순이었다.

Fig. 21의 재난안전 관리 공무원의 성과관리 개선 방안 평가에서는 각 개선방안에 대한 평가 안은 대부분 긍정적 평가를 받았다. 긍정적 평가를 받은 항목은 '보직 인센티 브 강화'(69.5\%), ‘수당제도 강화’(67.6\%), '가점제도 도 입’(65.4\%), ‘포상제도 강화’(64.8\%) 순이었다.

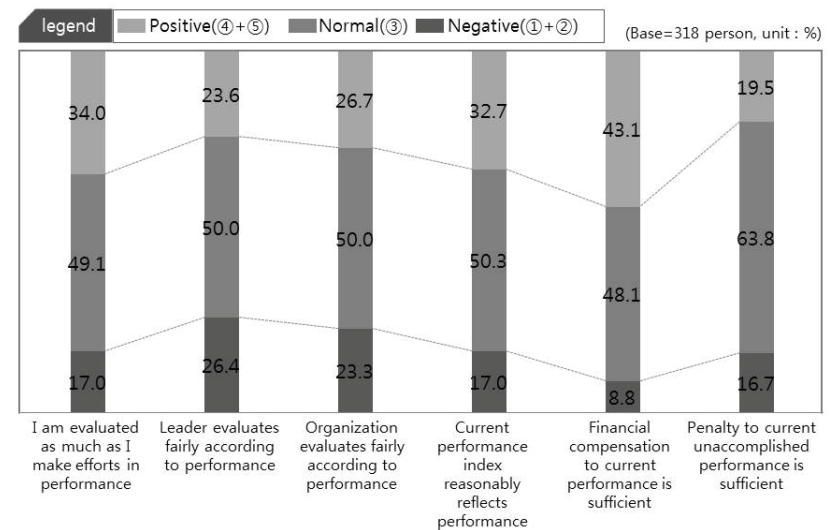

Fig. 20. Evaluation of the Performance Management Issues

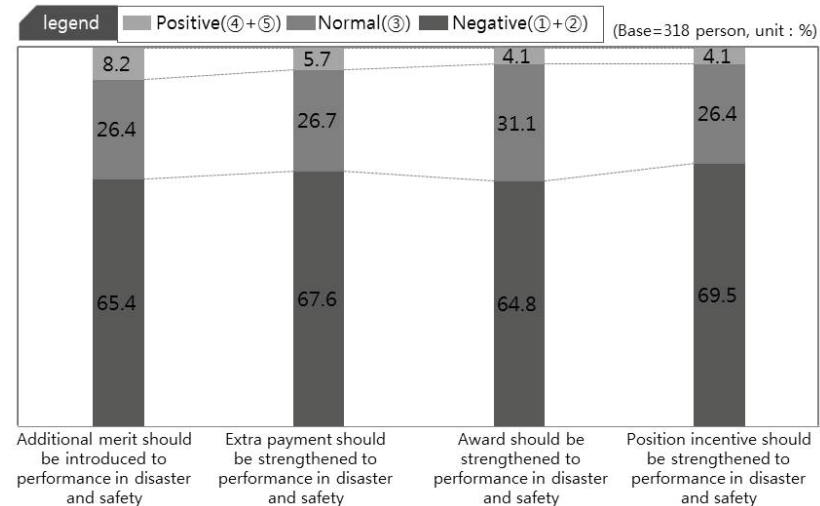

Fig. 21. Evaluation of Improvement of Performance Management

\section{3. 재난안전 인력 전문성 강화 방안}

\section{1 재난안전 인력의 배치 개선 및 보완대책}

\subsection{1 순환보직 개선방안}

재난안전 관리 공무원의 경우 재난발생시 또는 예상되는 때에도 상황근무와 같은 격무에 시달리어 개인의 건강 악화 등을 초래하는 경우도 있는데, 이 경우 순환보직은 휴식으로서 의 의미도 있으며, 순환보직을 통해 재난안전 관리 전문지식을 습득할 수 있으면, 공무원의 전문성 관점에서 도움이 될 수도 있다. 따라서, 순환보직의 단점을 최소화하고 장점을 극대화할 수 있는 방안의 강구가 필요한데, 재난안전 관리 분야 순환보직
의 발전을 위한 실행전략을 제시하면 다음과 같다.

첫째, 재난안전 관리업무 수행에 대한 보상 체계를 개선하 는 것이 가장 중요하다. 다양한 보상이 마련될 수 있다면 우수한 신규 인력의 충원이 강화되어 재난안전 관리부서의 조직전문성을 높이는데 기여 할 것이다.

둘째, 순환보직이 필요한 직무와 그렇지 않은 직무를 구분 하는 노력이 필요하다. 전문지식이나 경험이 중요하다면 순환보직보다는 장기 근무의 필요성이 높겠지만, 협업 및 조정 역량이나 개인의 자질의 필요성이 상대적으로 강하다 면 순환보직의 필요성이 높아질 것이다.

셋째, 재난안전 관리 기관의 위상을 강화하기 위한 노력이 필요하다. 여러 가지 승진, 보수, 교육, 복지 등 다른 부서와는 다른 차별적 보상이 가능해지면 우수인력의 진입이 활발해지 고 이에 따라 기관의 위상은 자연스럽게 높아질 수 있을 것이다.

넷째, 재난안전 관리부서 경험을 고위직 승진의 필수 요건 화 하는 것도 고려해 볼 필요가 있다. 이 경우 승진을 원하는 우수인력의 진입을 촉진할 것이므로 방재안전관리 부서의 전문성이 높아질 것으로 사료된다.

\subsection{2 민간전문가 채용 확대방안}

재난안전 관리 조직의 입장에서 전문성 있는 민간전문가 는 조직의 큰 자산이 되며, 민간전문가는 자신의 경력을 관리하기 위한 경로로 공직을 이용하기도 한다. 우수한 민간 전문가의 영입을 위해서는 민간의 수준에 상응하는 정도의 보수나 복지 혜택이 주어질 필요가 있을 것이다. 또한, 채용된 민간전문가와 기존 공무원들 간에는 문화 차이나 정체성 차이, 정책지향 등의 차이로 인한 갈등이 상존하는데, 이 과정에서 적응하지 못하고 공직사회를 이탈할 수도 있는 것이다. 이러한 관점에서는 부서 차원에서 리더의 적극적 역할과 다양한 통합프로그램의 실시, 인사공정성의 유지 등 다양한 통합관리 노력이 필요하다.

\subsection{3 인사교류 활성화 방안}

순환보직 관행이 제한되고 전보제한이나 전문직위 확대 등 직위분류제적 요소가 강화되는 경우, 전문성 향상을 위해 다음과 같은 인사교류를 활성화 할 필요가 있다. 첫째, 중앙과 지방 정부 상호 간 인사교류는 각 직무에 대한 이해를 통해 총체적 관점에서 재난안전 관리업무를 이해할 수 있게 된다. 둘째, 다른 부처의 재난안전 관리업무 수행은 재난안전 관리 업무의 시야를 넓힐 수 있으므로, 중앙정부 부처 간 인사교류 가 필요하다. 셋째, 민간 부문과의 인사교류도 적극적으로 활용할 필요가 있다.

또한, 전략적 관점에서 추가적으로 고려할 사항으로서 첫째, 인사교류 시 예방과 대비, 대응, 복구 공무원 간 인사교 류를 고려해볼 필요가 있다. 둘째, 인사교류 시에는 공무원의 책임성이나 조직충성도를 제고하는 방안을 마련하는 것도 중요하다. 셋째, 재난안전 관리 공무원 인사교류 시 전문성 
확보를 위해 적정체류 기간에 대한 고려가 필요하다.

\section{2 재난안전 인력 성과관리 개선 방안}

\subsection{1 성과관리 체계의 합리화 방안}

성과관리 체계의 합리화 방안의 실행전략을 위해 다음과 같은 사항을 고려하여야 한다. 첫째, 재난안전 관리 성과관리 체계의 공정성이 매우 중요하다. 둘째, 결과 중심의 평가 또는 과정 중심의 평가가 이루어 질 수 있도록 상황적 특수성 이 고려되고, 적합하고 특화된 성과관리가 필요하다. 셋째, 결과에 대한 평가와 과정에 대한 평가 등을 고려할 수 있는 합리적인 성과기준이 필요하다. 넷째, 평상시와 위기시 및 예방/대비/대응/복구 등을 고려하는 유형별 특수성이 반영된 성과관리 체계가 필요하다. 다섯째, 재난안전 관리업무의 수행은 조직 차원에서 유기적으로 움직여야 하므로 조직 중심의 성과관리가 필요하다.

\subsection{2 인센티브 설계 개선방안}

재난안전 관리 공무원에 대한 인센티브 설계의 개선을 위해 다음과 같은 사항을 고려하여야 한다. 첫째, 재난안전 관리업무 수행에 대하여 승진 또는 교육의 기회, 보직에 대한 우선권, 인사 상 가점 등 충분한 정도의 인사관리 상 보상이 필요하다. 둘째, 재난안전 관리업무 수행에 대한 사회적 보상인 인사 관리적, 금전적 보상을 제공하여 조직의 위상을 높이고 철저한 예방 및 대비를 통해 재난상황을 차단하거나 재난시 신속한 대응과 철저한 복구를 실현하도 록 하여야 한다. 또한, 중장기적으로 방재안전직렬의 특정직 화를 고려할 필요가 있다. 셋째, 재난안전 관리 성과관리에 리더의 관심이 높으면 성공할 가능성이 높으므로 성과관리 에 대한 기관장의 관심이 매우 중요하다. 넷째, 포상제도의 강화는 공무원의 전문성 향상에도 도움이 되므로, 재난안전 관리업무 성과에 충분한 포상제도가 필요하다. 다섯째, 재난 안전 관리업무 수행의 결과에 대한 책임이 필요하며, 책임을 다한 경우에는 적절한 면책규정도 마련될 필요가 있다.

\section{4. 결 론}

최근 여러 재난사고가 일어남에 따라 부각되고 있는 재난 안전 전문가의 전문성의 문제점과 대안을 제시하고자 재난 안전 관리 인력의 채용- 배치, 성과관리 등을 중심으로 문헌 조사와 공무원 대상 설문조사 에 의한 여러 자료를 확보하여 분석한 결과 다음과 같은 결론을 얻었다.

(1) 전문성이 매우 중요한 재난안전 분야에 순환보직 관행으 로 업무경험이 미흡한 인력이 배치되고, 연관조직 담당 자의 잦은 교체 및 현업시스템의 미비로 업무대처에 어려움이 있는 것으로 나타났으며, 전문성 결여를 극복
하기 위한 교육의 강도가 부족한 것으로 조사되었다.

(2) 전문성 결여는 해당분야의 업무의 강도 및 위험성에 비해 전문 인력에 대한 보상이나 평가체계로 인한 기피현상이 원인이 되는 것으로 조사되었다.

(3) 재난안전 관리 공무원의 전문성은 적절한 보상 및 평가 제도의 개선, 이를 통한 전문가의 책임감 고취, 근무여건의 개선, 순환보직의 문제점 해결을 통한 근속연수의 확대, 민간의 우수한 전문 인력을 채용하 는 방안 강구, 해당분야 교육 및 훈련 강도의 강화 등을 통해 전문성을 향상시킬 수 있는 개선방안을 제시하였다.

\section{감사의 글}

본 연구는 정부(행정안전부)의 재원으로 재난안전기술 개발사업단의 지원을 받아 수행된 연구이며[MOIS-재난 -2015-07], 행정안전부 방재안전분야 전문인력양성사업의 연구비 지원 및 광운대학교 2015년도 교내학술연구비 지원 에 의해 연구되었음.

\section{References}

Caiden, N. (1998) Public Service Professionalism for Performance Measurement and Evaluation. Public Budgeting \& Finance, Vol. 18, No. 2, pp. 35-52.

Choi, B.-D. (2003) Improving Specialty of Public Officials in Urban Planning Area of the Seoul Metropolitan Government. Journal of Local Government Studies, Vol. 15, No. 3, pp. 125-144.

Choi, S.Y., and Chang, J.W. (2009) Improving the Career Development Program for Public Employees. KIPA Research Report 2009-11.

Kearney, R.C., and Sinha, C. (1988) Professionalism and Bureaucratic Responsiveness: Conflict or Compatibility? Public Administration Review, Vol. 48, No. 1, pp. 571-579.

MOIS (Ministry of Interior and Safety) (2012) Press Releases: Training of Professional Officials for Strengthening of Disaster Management Capacity in Government.

Oh, H.S. (2006) A Study on the Process of Expertise Development and Key Factors. Journal of Vocational Education \& Training, Vol. 9, No. 2, pp. 193-216.

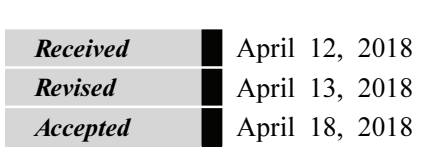


